\title{
Capabilities of Fe-Functionalized Biochar to Decrease Soil Pb and As Phytodisponibility
}

\author{
Manhattan Lebrun ${ }^{1,3}$, Florie Miard ${ }^{1}$, Sullivan Renouard ${ }^{2}$, Romain Nandillon ${ }^{1}$, Gabriella S. Scippa ${ }^{3}$, \\ Domenico Morabito ${ }^{1}$, Sylvain Bourgerie ${ }^{1}$ \\ ${ }^{1}$ Université d'Orléans, LBLGC INRA USC1328 \\ rue de Chartres, BP 6759, 45067 Orléans Cedex 2, France \\ manhattan.lebrun@etu.univ-orleans.fr; florie.miard@univ-orleans.fr; romain.nandillon@univ-orleans.fr; \\ domenico.morabito@univ-orleans.fr; sylvain.bourgerie@univ-orleans.fr \\ ${ }^{2}$ Université d'Orléans, LBLGC INRA, USC 1328- Antenne Scientifique Universitaire de Chartres, \\ 21 Rue de Loigny La Bataille, 28000 Chartres, France \\ sullivan.renouard@univ-orleans.fr \\ ${ }^{3}$ Università degli Studi del Molise, Dipartimento di Bioscienze e Territorio \\ 86090, Pesche, Italy \\ scippa@unimol.it
}

\section{Extended Abstract}

Biochar, produced by the pyrolysis of biomass under low oxygen conditions, has gathered attention in the last few years due to its capability to reduce metal(loid)s bioavailability and mobility in soils [1], as well as its beneficial effects on soil fertility. Indeed, biochar amendment to polluted soil induced usually an increase of $\mathrm{pH}$, water holding capacity and nutrient contents, associated with a decrease of metal(loid)s concentrations in soil pore water [2], through sorption. However, biochar has been shown efficient in sorbing cations pollutants, like $\mathrm{Pb}$, but present a low sorption capacity towards anions like As. This contrasted behaviour poses a problem, as most polluted soils are multi-contaminated, with both cations and anions pollutants. One of the solution to overcome such problem is to functionalized biochar, by modifying its surface. However, most studies actually focused on functionalization effect on metal(loid)s sorption towards batch experiments, and only a few dealt with modified-biochar incorporation to the soil. Therefore, this study aimed (i) to assess the sorption capacity of hardwood biochars, harbouring different particle sizes, towards $\mathrm{Pb}$ and $\mathrm{As}$; (ii) to evaluate the effect of a Fe-functionalization on $\mathrm{Pb}$ and As sorption and (iii) to validate the results, in a phytotoxicity test using Phaseolus vulgaris as bioindicator plant. The batch experiments showed all four biochars were able to efficiently sorb $\mathrm{Pb}$, the fine biochars showing higher sorption values than the coarse biochars ( $85 \%$ vs $40 \% \mathrm{~Pb}$ sorption). As sorption was very low (less than 5\%). Fe-coating increased As sorption value (by 10-fold), while having no effect on $\mathrm{Pb}$ sorption. However, when incorporated in the soil, Fe-coated biochar did not improve soil physico-chemical properties compared to the pristine biochar; especially it did not reduce As soil pore water concentrations $(0.13 v s 0.10 \mathrm{mg} / \mathrm{L}$ As concentrations). Finally, bean plant did not show differences in terms of biomass production between the two biochars incorporated into polluted soil, demonstrating that Fe-functionalization did not improve biochar capacity to decrease soil toxicity.

\section{References}

[1] H. Ali, E. Khan, M. A. Sajad, "Phytoremediation of heavy metals-Concepts and applications," Chemosphere, vol. 91, no. 7, pp. 869-881, 2013.

[2] M. Lebrun, F. Miard, R. Nandillon, J. C. Léger, N. Hattab-Hambli, G. S. Scippa, S. Bourgerie, D. Morabito, “Assisted phytostabilization of a multicontaminated mine technosol using biochar amendment: early stage evaluation of biochar feedstock and particle size effects on As and $\mathrm{Pb}$ accumulation of two Salicaceae species (Salix viminalis and Populus euramericana)," Chemosphere, vol. 194, pp. 316-326, 2018. 